Article

\title{
Assessment of Eco-Environmental Stress in the Western Taiwan Straits Economic Zone
}

\section{Longyu Shi ${ }^{1, *}$ and Shuncheng Yang ${ }^{1,2}$}

1 Key Laboratory of Urban Environment and Health, Institute of Urban Environment, Chinese Academy of Sciences, 1799 Jimei Road, Xiamen 361021, China;

E-Mail: scyang@iue.ac.cn

2 University of Chinese Academy of Sciences, Beijing 100049, China

* Author to whom correspondence should be addressed; E-Mail: lyshi@iue.ac.cn; Tel.: +86-592-619-0690.

Academic Editor: Marc A. Rosen

Received: 24 December 2014 / Accepted: 26 February 2015 / Published: 5 March 2015

\begin{abstract}
Eco-environmental stress refers to the pressure borne by the environment in sustaining the pre-existing non-industrialized state and/or in counteracting adverse impacts caused by natural and human factors. The present article introduces the concept, research progress, and method for assessing eco-environmental stress. An eco-environmental stress index (ESI) is established to assess the eco-environmental stress of 13 cities in the Western Taiwan Straits Economic Zone (hereafter referred to as the Economic Zone) during the period from 2000 to 2010 . The research provides a reference for the strategic planning of industrial development and environmental protection. The results show that the overall eco-environmental stress of the Economic Zone was slight and did not have significant change during the past 10 years. The cities with the most severe eco-environmental stress are distributed in the north and south of the Economic Zone. Most areas of Fujian Province have a low degree of eco-environmental stress, a situation that is being constantly improved. The regions with high atmospheric and water pollutant emissions are concentrated in the northern, middle, and southern coastal regions of the Economic Zone. The pollutant emissions of coastal cities are higher than those of inland cities. In the future, ecological restoration and compensation mechanisms should be established for regions where environmental protection and remediation is urgently needed.
\end{abstract}


Keywords: environmental stress; eco-environmental stress; environmental assessment; environmental research; industrial development; Western Taiwan Straits Economic Zone

\section{Introduction}

Eco-environmental stress refers to the pressure borne by the environment in sustaining the pre-existing non-industrialized state and/or in counteracting adverse impacts caused by natural and human factors. The long-term exploitation and overuse of natural resources, and neglecting compensatory ecological restoration and reconstruction, aggravate eco-environmental stress. The term "stress" originally referred to threat and pressure, and was first used in the field of stress physiology as a collective term for adverse environmental factors that were challenging organisms (Sun [1] 1999). As the theory of stress ecology developed, the term has now come to refer to the sum of all factors that affect an ecosystem. Stress can be construed in both positive and adverse senses. Tang et al. [2] (2007) noted that eco-environmental stress refers to the pressure borne by the natural resources in the environment brought on by natural and human factors. Miao et al. [3] (2001) defined it as the pressure imposed by human activities on the natural resources of the environment. Sun et al. [1] (1999) explained the term as the acting factors responsible for the changes, reactions, or functional disorder of the environment. Natural factors contributing to eco-environmental stress include extreme climatological and geological phenomena, and changes of temperature and humidity.

This article considers eco-environmental stress as consisting of natural and human factors. The finding is that the environment is passively and adversely influenced by stress factors and this should be highlighted. Therefore, eco-environmental stress is defined as the pressure borne by the environment in maintaining the pre-existing non-industrialized state, or in counteracting adverse impacts brought by natural and human factors. The population is the main part of the earth's development, it is also the main body of social consumption. Too much of the population will cause stress on the ecological environment. Of all human activities, pollutant discharge to the ecological environment is most direct. Due to the various types and forms of pollutants, all kinds of environmental problems occurred in recent years. In south China, the frequency of acid rain has increased, industrial and agricultural source of pollution cannot be effectively control, and heavy metal, organic and radioactive pollutants keep accumulating in the soil: all of these are the consequences of eco-environmental stress.

There are other phrases with meanings similar to eco-environmental stress. They include eco-environmental impact and eco-environmental interference. Some researchers fail to clearly distinguish between these phrases, resulting in misuse or even abuse of the terminology. Eco-environmental impact refers to ecosystem changes brought about by non-polluting human activities (Gao [4] 2007). The concept was put forward to distinguish those changes from those caused by eco-environmental pollution coming from industrial, agricultural, and domestic sources. Such impacts may be beneficial or detrimental. Compared to eco-environmental stress, eco-environmental impact highlights consequences rather than causes.

Eco-environmental interference refers to the intermittent and abrupt action of external factors, or the continuous abnormal fluctuations of external factors. Compared with eco-environmental stress, 
eco-environmental interference emphasizes short-term, sudden changes of eco-environmental factors. Though the range of its action may be small, the outcome of its action can be significant. When the interference vanishes, the ecosystem returns its pre-existing non-industrialized state. Borics et al. [5] (2013) compared the definitions of eco-environmental stress and eco-environmental interference. They contended that the frequency of occurrence, and whether the ecosystem can return its pre-existing non-industrialized state, are the two major standards for distinguishing these terms.

At present, there have been many studies on the assessment methods of eco-environmental stress at home and abroad, wherein the typical method is the eco-environmental stress index method. Eco-environmental stress index (ESI) is a new and practical method to evaluate the stress of ecological environment caused by regional economic growth, with simple calculation and strong comprehensiveness, and can directly reflecting the state and changing trend of eco-environmental stress, so it is praised highly by some scholars. Most scholars use an eco-environmental index to assess the eco-environmental stress of a specific region. In most circumstances, they choose the indexes that reflect the most prominent eco-environmental problems in assessment, so as to orient policy toward those problems. Inhaber [6] (1974) established an eco-environmental index to calculate the eco-environmental quality of the entirety of Canada. Due to the short duration of that research, however, the interannual variations of eco-environmental quality could not be characterized. Hope et al. [7] (1992) used nine eco-environmental indexes to estimate an annual compound eco-environmental index during the period 1980 to 1988. The weight of each index was determined by public survey. The nine indexes selected for their study, however, could not fully represent the environmental status. Adriaanse [8] (1993) assessed the impact of seven major environmental problems, including climate change, depletion of the ozone layer, acidification of soil, and eutrophication of water in Holland. Puolamaa et al. [9] (2013) developed a system of environmental indexes for assessing 10 major environmental problems caused by human economic activities. Other scholars have modified the concepts and methods for assessing eco-environmental stress. For example, Giannetti et al. [10] (2009) adopted a paraconsistent logic method to analyze the influence of factor weights obtained by expert scoring on the generation of a final index. In the present work, an ESI was established to assess the effect of population density, atmospheric pollution, and water pollution in 13 prefecture-level cities in the Western Taiwan Straits Economic Zone (hereafter referred to as the Economic Zone) during the period from 2000 to 2010. The research aims to provide a reference for the strategic planning of industrial development and eco-environmental protection.

\section{Methods and Data}

\subsection{Research Area}

The Economic Zone belongs to China's coastal economic zone, and plays an important role in the strategic planning of regional economic development in China. The Economic Zone is the major area for a new round of regional economic adjustments and the expansion of China's total economic volume. The Economic Zone encompasses nine prefecture-level cities in Fujian Province; Shantou, Chaozhou, and Jieyang in Guangdong Province; and Wenzhou in Zhejiang Province: a total of 13 prefecture-level cities (Figure 1), covering a total land area of 145.2 thousand $\mathrm{km}^{2}$, which accounts for 1.51 percent of China's land area. 


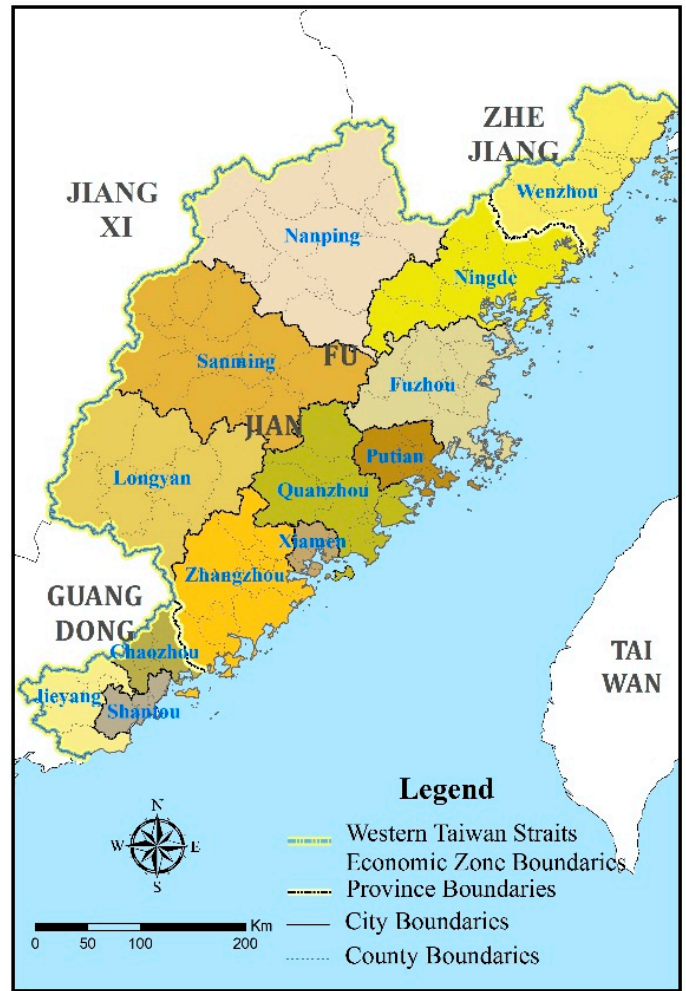

Figure 1. Administration division map of the Western Taiwan Straits Economic Zone.

\subsection{Index System}

The definition of modern regional development covers a total quality of environmental and ecological effects (Cengiz [11] 2013). Given the severe atmospheric and water pollution problems of the Economic Zone, analytical hierarchy process (AHP) was employed to divide the index system into three layers: target, criterion, and index. AHP is a combination of qualitative and quantitative analysis. The core of AHP is to decompose a problem into several levels and indexes. After judging the significance of all the indexes, a judgment matrix will be established. Scholars can obtain weights of different indexes by computing the maximum eigenvalues of the judgment matrix and the corresponding eigenvectors. Five indexes belonging to two categories were chosen to establish an eco-environmental stress index system (Figure 2).

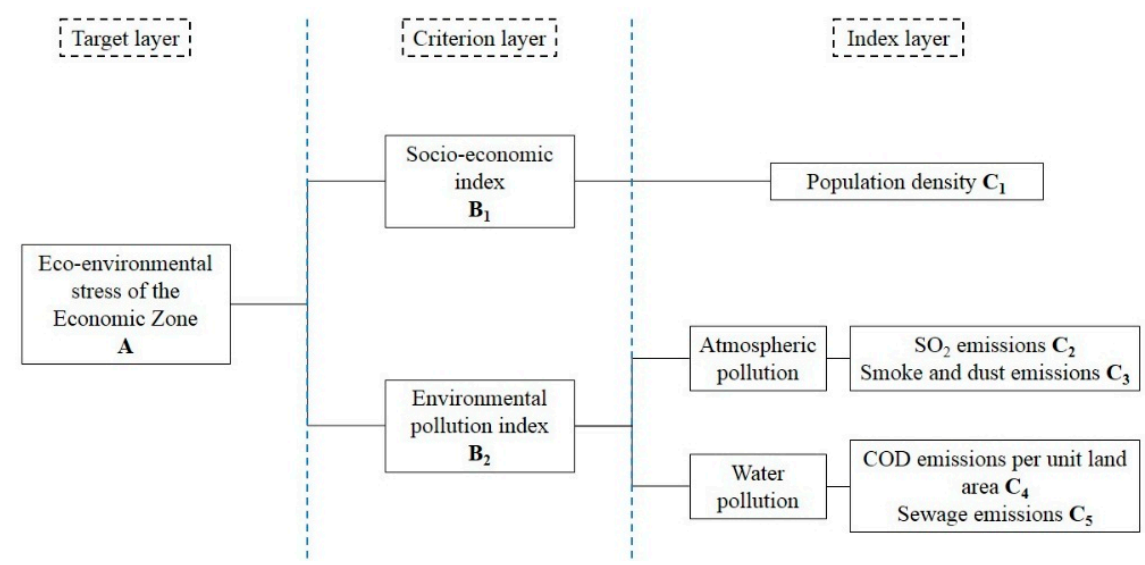

Figure 2. Eco-environmental stress index system for the Economic Zone. 


\subsection{ESI Methods}

An ESI was established for this paper to reflect the eco-environmental stress of the Economic Zone. Eco-environmental stress is closely connected with human activities, human beings are the main source of the pressure but also a receptor at the same time, so the population itself will bring stress to the ecological environment. Different from other research approaches, population density is employed to be one of the resources and the energy consumption index in the index system. It can fully characterize the impact of city size and economic effects on the environment. Moreover, population density is linearly related to resources consumption so that it is a good alternative to resources consumption. Other chosen indexes are all aimed to reflect the most prominent eco-environmental problems in the research area, so as to orient policy toward those problems. The weight of each factor in the index was determined by principal component analysis (PCA). Commonly used methods of determining the weight, e.g., the empirical method and Delphi expert consensus have a strong subjectivity. PCA is used to fully tap the information entropy and give the objective weights. PCA is a multivariate modeling and analysis technique. PCA is a way of identifying patterns in data, and expressing the data in such a way as to emphasize their similarities and differences. It can compress the data, that is, by reducing the number of dimensions without much loss of information based on their similarities and differences, and define a limited number of "principal components" which describe independent variation structures in the data. When more than three variables have been measured, visualization of the data by various plotting systems is then possible (Kamal-Eldin and Andersson [12]). The weight of each factor was computed by using factor analysis of SPSS 20.0. The data used in this study were from the China City Statistical Yearbooks from 2001, 2006 and 2011.

$$
E S I_{i}=\sum_{j=1}^{n} \mathrm{ES}_{j} \times \mathrm{ES} r_{i j}
$$

where

ESI $_{i}$ is the eco-environmental stress index of the $i$ th region

$\mathrm{ESw}_{\mathrm{j}}$ is the relative weight of each eco-environmental stress

$\mathrm{ESr}_{\mathrm{ij}}$ is the standardized value of each index in the $i$ th region

$\mathrm{j}$ is the given stress factor.

The values of indexes were normalized to $[0,1]$ interval according to the following normalization formula:

$$
\begin{aligned}
Y_{i} & =\frac{X_{i}-X_{\min }}{X_{\max }-X_{\min }}(\text { Positive index }) \\
Y_{i} & =\frac{X_{\max }-X_{i}}{X_{\max }-X_{\min }}(\text { Negative index })
\end{aligned}
$$

where

$\mathrm{X}_{\mathrm{i}}$ is the original value of the index

$\mathrm{Y}_{\mathrm{i}}$ is the normalized value of the extreme of $\mathrm{X}_{\mathrm{i}}$

$\mathrm{X}_{\max }$ and $\mathrm{X}_{\min }$ are the maximum and the minimum of each index in the research area.

The ESI is composed of two parts, the resource and energy consumption index (RECI) and environmental performance index (EPI). RECI characterizes the ecological pressure generated by 
regional economic development, and EPI characterizes the environmental pollution pressure generated by regional economic development. Hence, RECI and EPI can be used to estimate the main sources of eco-environmental stress. Population density is chosen as a RECI index. $\mathrm{SO}_{2}$ emissions, smoke and dust emissions, COD (Chemical Oxygen Demand) emissions per unit land area and sewage emissions are chosen as EPI indexes to represent the prominent eco-environmental problems in the Economic Zone. The calculation formula is as follows:

$$
\mathrm{ESI}=\mathrm{RECI} \times W_{1}+\mathrm{EPI} \times W_{2}
$$

where

ESI indicates the eco-environmental stress index

RECI indicates resources energy consumption index

EPI indicates environmental performance index

$\mathrm{W}_{1}$ and $\mathrm{W}_{2}$ are the weights of these two sub-indices

RECI and EPI are calculated as follows:

$$
\begin{aligned}
\mathrm{RECI} & =\sum_{i=1}^{n} R E C I_{i} \times P_{i} \\
\mathrm{EPI} & =\sum_{j=1}^{m} E P I_{j} \times P_{j}
\end{aligned}
$$

where

RECI $_{i}$ is the value of the $\mathrm{i}$-th RECI

$P_{i}$ is the weight of the $i-t h$ RECI

$\mathrm{EPI}_{\mathrm{j}}$ is the value of the $\mathrm{j}$-th $\mathrm{EPI}$

$P_{j}$ is the weight of the $j$-th EPI

The stress indices of each index are calculated according to the following formulas:

$$
\begin{gathered}
R E C I_{i}=R E C_{i} / \operatorname{Max}\left(R E C_{i}\right) \times 100(\mathrm{i}=1,2, \ldots, \mathrm{n}) \\
E P I_{j}=E P_{j} / \operatorname{Max}\left(E P_{j}\right) \times 100(\mathrm{j}=1,2, \ldots, \mathrm{n})
\end{gathered}
$$

where

$R E C_{i}$ and $E P_{j}$ are the actual values of the $i$-th RECI and the $j$-th EPI, respectively.

$\operatorname{Max}\left(\mathrm{REC}_{\mathrm{i}}\right)$ and $\operatorname{Max}\left(\mathrm{EP}_{\mathrm{j}}\right)$ are the maximum values of all RECIs and EPIs.

\section{Research Results}

\subsection{Result Analysis of Each Index of ESI}

\subsubsection{Population Density}

Permanent population per unit land area (persons $/ \mathrm{km}^{2}$ ) was used to characterize the stress imposed by population density on the environment of the Economic Zone (Figure 3). On the whole, the population 
density of the Economic Zone has been rising every year, and rose by $10.1 \%$ during the period studied. In terms of spatial distribution, the population density increases from west to east across the Economic Zone. The cities with high population density are concentrated in southeastern coastal region, while the population density is lower in the inland cities. There are also significant differences in population density between different parts of individual cities. Take Fuzhou in 2010 as an example. The Taijiang District was the district with the highest population density; it was 223 times that of the population density in Yongtai County, the county with the lowest population density. In terms of temporal distribution, there has been an inconsistent variation in the population density of different parts of the Economic Zone in the three of each year studied. Huli District of Xiamen has had the fastest growth of population density: $736 \%$ in 10 years during the period studied. Nan'ao County of Shantou has the largest decrease in population density: nearly $96 \%$ in 10 years during the period studied.
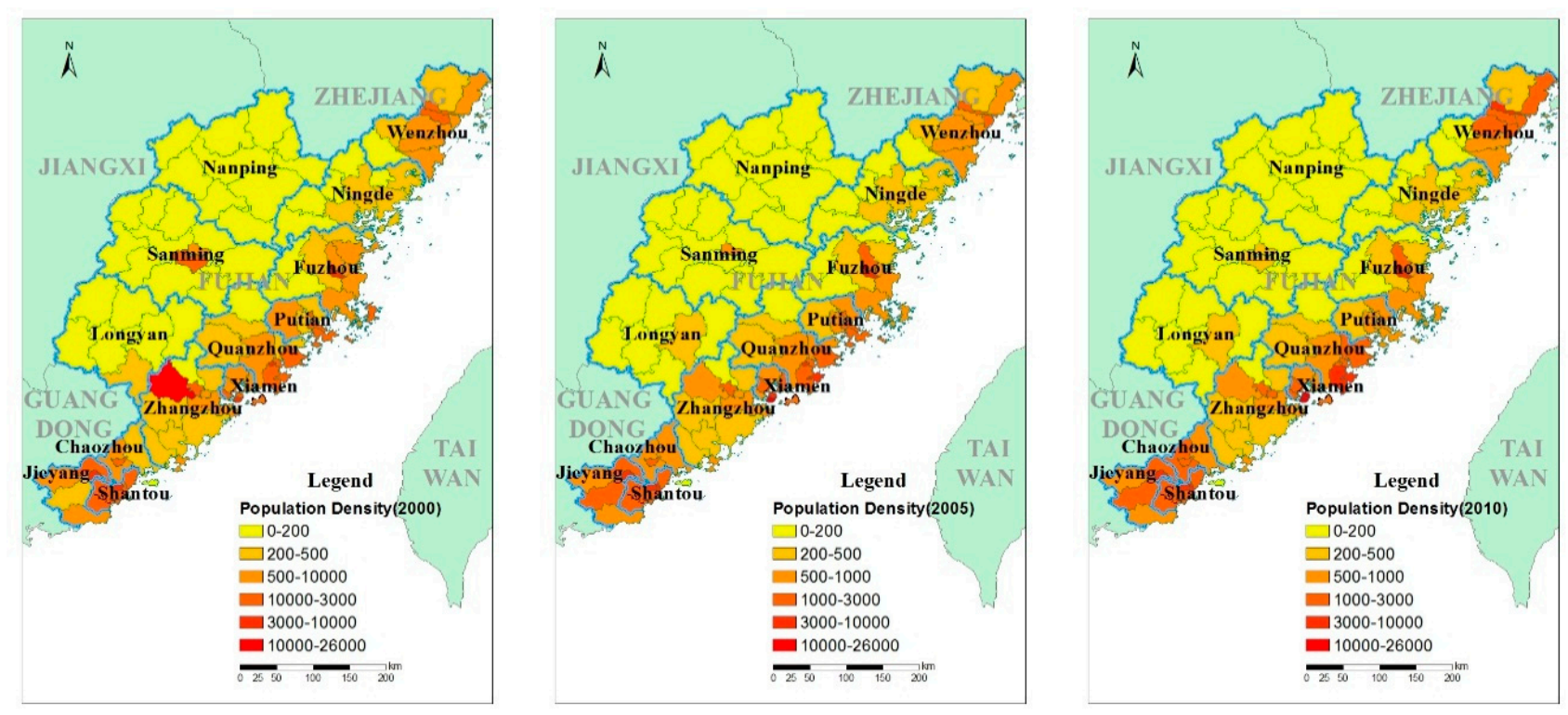

Figure 3. Population density of the Western Taiwan Straits Economic Zone (persons $/ \mathrm{km}^{2}$ ).

\subsubsection{Atmospheric Pollution}

\subsubsection{Industrial $\mathrm{SO}_{2}$ Emissions}

In the past 10 years, over the period studied, the industrial $\mathrm{SO}_{2}$ emissions of the Economic Zone showed an increasing trend (Table 1). The mean $\mathrm{SO}_{2}$ emissions per city increased from 1.99 ton $/ \mathrm{km}^{2}$ in 2000 to 4.10 ton $/ \mathrm{km}^{2}$ in 2010 . The $\mathrm{SO}_{2}$ emissions per unit land area were the highest in Xiamen and the lowest in Ningde in the three of each year studied. The $\mathrm{SO}_{2}$ emissions of the Economic Zone in 2005 show an obvious variation in spatial distribution. The cities with high $\mathrm{SO}_{2}$ emissions are concentrated in the north, middle, and south coastal regions of the Economic Zone. The $\mathrm{SO}_{2}$ emissions of the Economic Zone in 2010 were more evenly distributed, with a low probability of the occurrence of extremes. In 2010, the $\mathrm{SO}_{2}$ emissions of Shantou increased significantly, showing a 232.82\% rise from 2005.

There is a trend of $\mathrm{SO}_{2}$ emissions spreading away from Economic Zone. The $\mathrm{SO}_{2}$ emissions of inland cities showed smaller increases than did those of the coastal cities. The spatial distribution of $\mathrm{SO}_{2}$ emissions correlated with the GDP of the cities. The cities with high GDP are concentrated in coastal 
regions of the Economic Zone, where GDP is increasing every year. Primary industry still occupies the dominant role in inland cities, whereas secondary industry, represented by light industry, dominates in coastal cities. As a result, the $\mathrm{SO}_{2}$ emissions of coastal cities were significantly higher than those of inland cities. In recent years, secondary industry is being rapidly developed in inland cities. Heavy industry, which was once the weak link in China's industrial structure, is also being upgraded and strengthened. It has been predicted that atmospheric pollution in the Economic Zone will worsen in the future, and that the space distribution pattern of more severe atmospheric pollution in coastal regions than in inland regions may be disrupted.

Table 1. Industrial $\mathrm{SO}_{2}$ emissions in the Economic Zone (ton $\left./ \mathrm{km}^{2}\right)$.

\begin{tabular}{cccc}
\hline \multirow{2}{*}{ City } & Industrial SO & Emissions in Western Taiwan Straits Economic Zone (ton/: $\left.\mathbf{k m}^{\mathbf{2}}\right)$ \\
\cline { 2 - 4 } & $\mathbf{2 0 0 0}$ & $\mathbf{2 0 0 5}$ & $\mathbf{2 0 1 0}$ \\
\hline Fuzhou & 3.7 & 8.7 & 6.9 \\
Xiamen & 25.4 & 43.1 & 31.3 \\
Putian & 1.4 & 8.0 & 7.9 \\
Sanming & 1.7 & 3.6 & 3.0 \\
Quanzhou & 1.7 & 5.4 & 4.2 \\
Zhangzhou & 0.5 & 1.1 & 3.6 \\
Nanping & 0.6 & 1.4 & 1.2 \\
Longyan & 1.6 & 3.2 & 2.8 \\
Ningde & 0.5 & 0.4 & 0.9 \\
Shantou & 13.7 & 13.1 & 30.5 \\
Chaozhou & 0.8 & 1.3 & 4.9 \\
Jieyang & 1.7 & 0.4 & 5.8 \\
Wenzhou & 3.8 & 6.8 & 5.3 \\
\hline Mean Value & 1.99 & 3.96 & 4.10 \\
\hline
\end{tabular}

\subsubsection{Industrial Smoke and Dust Emissions}

Of the three provinces in the Economic Zone, Guangdong had a lower level of industrial smoke and dust emissions than the other two provinces (Figure 4). With the exception of Quanzhou, all other inland cities of Fujian Province had higher levels of industrial smoke and dust emissions than the coastal cities. In 2010, the total smoke and dust emissions of the Economic Zone decreased slightly from 2005. There was a significant reduction, however, in the number of cities that were not significantly affected by industrial smoke and dust pollution. The number of cities with smoke and dust emissions lower than 2252 tons was zero in 2010, as opposed to three in 2005. With the exception of Quanzhou, the smoke and dust emissions of other cities in Fujian Province increased in 2010 from 2005.

In terms of spatial distribution, the cities with the highest industrial smoke and dust emissions in 2005 were located mainly in the south of Fujian Province. The differences in emissions among the cities of the Economic Zone were significant. The 2010 spatial distribution of smoke and dust emissions of the Economic Zone showed a flattening trend, with only a few cities with extremely high or low emissions. There was also a narrowing of the differences in smoke and dust emissions among the cities. China's industry has been developing rapidly, though at the cost of high energy consumption and high pollution. The Economic Zone has a developed light industry, which is one of the reasons for its GDP being lower 
than the national average. Thus, the environmental pollution caused by industrial production in the Economic Zone is less than in other regions. Industrial smoke and dust poses a great threat to human health, causing damage to the upper respiratory tract. The Economic Zone experiences a subtropical monsoon climate, which facilitates the diffusion and migration of atmospheric pollutants. However, if this pollution is not properly controlled, it could lead to greater and more frequent occurrences of smog in China's southeastern coastal regions and the countries neighboring those regions.

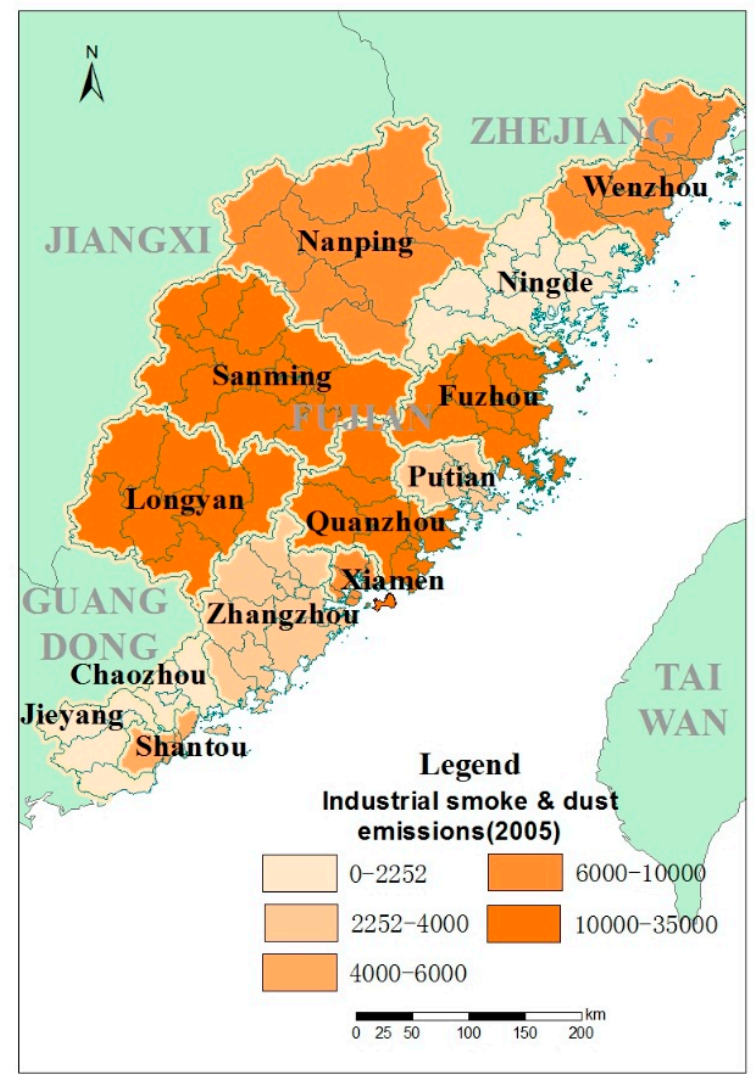

(a)

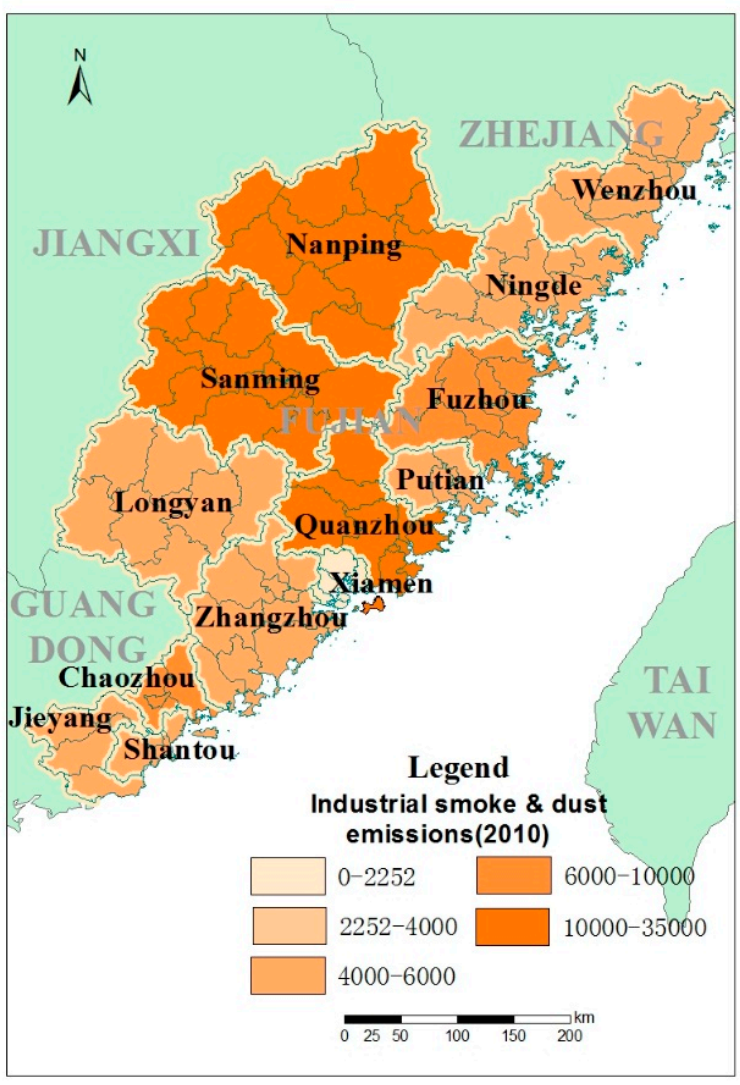

(b)

Figure 4. Industrial smoke and dust emissions in the Economic Zone (ton $\left./ \mathrm{km}^{2}\right)$.

\subsubsection{Water Pollution}

\subsubsection{COD Emissions Per Unit Land Area}

In the past ten years during the period studied, COD emissions of the Economic Zone (COD emissions per unit land area, ton $/ \mathrm{km}^{2}$ ) increased and then decreased (Table 2). The average COD emissions per city increased from $3.47 \mathrm{ton} / \mathrm{km}^{2}$ in 2000 to 4.12 ton $/ \mathrm{km}^{2}$ in 2005 , and then decreased to $3.86 \mathrm{ton} / \mathrm{km}^{2}$ in 2010. The cities with the highest COD emissions per unit land area represented a small proportion of the total land area of the Economic Zone. The pollution was most serious in the northern, middle and southern parts of the Economic Zone, but there was no trend of this particular pollution spreading to other regions. In the past 10 years, during the period studied, water quality as characterized by COD has improved in Wenzhou. In contrast, water quality by this standard has deteriorated in Xiamen and Shantou. For the other cities, the COD emissions per unit land area did not change significantly. 
Table 2. Industrial COD emissions Industrial $\mathrm{SO}_{2}$ emissions in Western Taiwan Straits Economic Zone (ton $\left./ \mathrm{km}^{2}\right)$.

\begin{tabular}{cccc}
\hline \multirow{2}{*}{ City } & \multicolumn{3}{c}{$\begin{array}{c}\text { Industrial COD Emissions Industrial } \mathbf{S O}_{\mathbf{2}} \text { Emissions } \\
\text { in Western Taiwan Straits Economic Zone (ton/: } \mathbf{~ m}^{\mathbf{2}} \text { ) }\end{array}$} \\
\cline { 2 - 4 } & $\mathbf{2 0 0 0}$ & $\mathbf{2 0 0 5}$ & $\mathbf{2 0 1 0}$ \\
\hline Fuzhou & 4.8 & 4.4 & 4.2 \\
Xiamen & 14.4 & 35.4 & 31.4 \\
Putian & 2.7 & 4.7 & 4.5 \\
Sanming & 2.3 & 2.0 & 2.0 \\
Quanzhou & 5.6 & 7.7 & 7.2 \\
Zhangzhou & 2.3 & 2.2 & 2.1 \\
Nanping & 1.7 & 1.7 & 1.7 \\
Longyan & 1.3 & 1.5 & 1.5 \\
Ningde & 1.4 & 2.5 & 2.4 \\
Shantou & 3.3 & 17.7 & 37.1 \\
Chaozhou & 0.0 & 0.0 & 6.9 \\
Jieyang & 5.1 & 8.0 & 7.1 \\
Wenzhou & 12.7 & 10.7 & 4.4 \\
\hline Mean Value & 3.47 & 4.12 & 3.86 \\
\hline
\end{tabular}

The cities that experienced the highest rates of increasing COD emissions per unit land area from 2000 to 2005 were Shantou and Xiamen, with values of $435.7 \%$ and $146.7 \%$, respectively. The cities with the lowest rates of reduction over that same time period were Wenzhou and Sanming. The city with the highest rate of increasing COD emissions from 2005 to 2010 was Shantou, with a value of 109.8\%. The cities with the highest rates of reduction were Wenzhou and Jieyang, with values of $58.8 \%$ and $11.9 \%$, respectively.

\subsubsection{Sewage Emissions}

In the past 10 years, during the period studied, the sewage emissions per unit land area in the Economic Zone showed an increasing trend on the whole. The average sewage emissions per city increased from 24 thousand ton $/ \mathrm{km}^{2}$ in 2000 to 32 thousand ton $/ \mathrm{km}^{2}$ in 2005 , and 45 thousand ton $/ \mathrm{km}^{2}$ in 2010 . The rates of increase were $33.3 \%$ and $40.6 \%$, respectively. Shantou was the city with the highest sewage emissions per unit land area in 2000, with a value of 100 thousand ton $/ \mathrm{km}^{2}$. Xiamen had the highest sewage emissions per unit land area in 2005, with a value of 110 thousand ton $/ \mathrm{km}^{2}$. Xiamen was still the city with the highest sewage emissions per unit land area in 2010, with a value of 155 thousand ton $/ \mathrm{km}^{2}$. Ningde was the city with the lowest sewage emissions per unit land area in 2000, with a value of 2 thousand ton $/ \mathrm{km}^{2}$. The sewage emissions per unit land area of Longyan in 2005 was 5 thousand ton $/ \mathrm{km}^{2}$. The sewage emissions per unit land area of Longyan and Nanping in 2010 were 6 thousand ton $/ \mathrm{km}^{2}$, respectively. The cities with high sewage emissions are concentrated in the middle part of the Economic Zone, and there were no significant differences in this value between coastal cities and inland cities. 


\subsection{Overall Analysis of the Eco-Environmental Stress Index Assessment}

In the assessment index system, population density, atmospheric pollution, and water pollution are all negative indexes. Each index was normalized before principal component analysis. The first principal component for the year 2000 accounts for $71.3 \%$ of the variable; the first principal component for the year 2005 accounts for $81.8 \%$ of the variable; the first principal component for the year 2010 accounts for $97.6 \%$ of the variable. The weights of each index for the three years are shown in Table 3 . The calculation results of ESI are shown in Table 4.

Table 3. Proportions of each eco-environmental stress index (ESI) in Western Taiwan Straits Economic Zone.

\begin{tabular}{|c|c|c|c|}
\hline Year Index & 2000 & 2005 & 2010 \\
\hline Density of population & 0.31 & 0.30 & 0.33 \\
\hline Atmospheric pollution & 0.37 & 0.34 & 0.33 \\
\hline Water pollution & 0.32 & 0.36 & 0.34 \\
\hline
\end{tabular}

Table 4. Calculation results of ESI in Western Taiwan Straits Economic Zone.

\begin{tabular}{cccc}
\hline \multirow{2}{*}{ City } & \multicolumn{3}{c}{ Index of Eco-Environmental Stress } \\
\cline { 2 - 4 } & $\mathbf{2 0 0 0}$ & $\mathbf{2 0 0 5}$ & $\mathbf{2 0 1 0}$ \\
\hline Fuzhou & 0.22 & 0.17 & 0.15 \\
Xiamen & 1.00 & 1.00 & 0.91 \\
Putian & 0.15 & 0.18 & 0.18 \\
Sanming & 0.04 & 0.03 & 0.02 \\
Quanzhou & 0.23 & 0.20 & 0.17 \\
Zhangzhou & 0.06 & 0.04 & 0.07 \\
Nanping & 0.00 & 0.00 & 0.00 \\
Longyan & 0.02 & 0.02 & 0.02 \\
Ningde & 0.01 & 0.02 & 0.02 \\
Shantou & 0.68 & 0.64 & 1.00 \\
Chaozhou & 0.08 & 0.08 & 0.19 \\
Jieyang & 0.28 & 0.21 & 0.24 \\
Wenzhou & 0.44 & 0.24 & 0.16 \\
\hline
\end{tabular}

The eco-environmental stress of the Economic Zone was graded. The normalized values of each level of ESI were 0-0.2, 0.2-0.4, 0.4-0.6, 0.6-0.8, and 0.8-1.0, corresponding to very good, good, moderate, poor, and very poor, respectively. A map was plotted for each level of ESI. The grading results of ESI of the Economic Zone are shown in Figure 5.

The overall condition of the Economic Zone's eco-environmental stress has not shown statistical differences during the period studied. Cities in the Economic Zone did not suffer from severe eco-environmental stress. The number of cities with an ESI of 0-0.2 has increased from 7 to 10, accounting for $76.9 \%$ of all cities in the Economic Zone. The number of cities with an ESI of $0-0.4$ has increased from 9 to 11 , accounting for $84.6 \%$ of all cities. The cities with an ESI below the moderate level accounted for $15.4 \%$ of all cities in 2010. In Chaozhou, the eco-environmental stress has intensified 
quantitatively. In terms of spatial distribution, the cities with the highest eco-environmental stress are mostly distributed in the north and south of the Economic Zone, i.e., the cities of Zhejiang and Guangdong provinces. In most parts of Fujian Province, the eco-environmental stress is mild and improving.
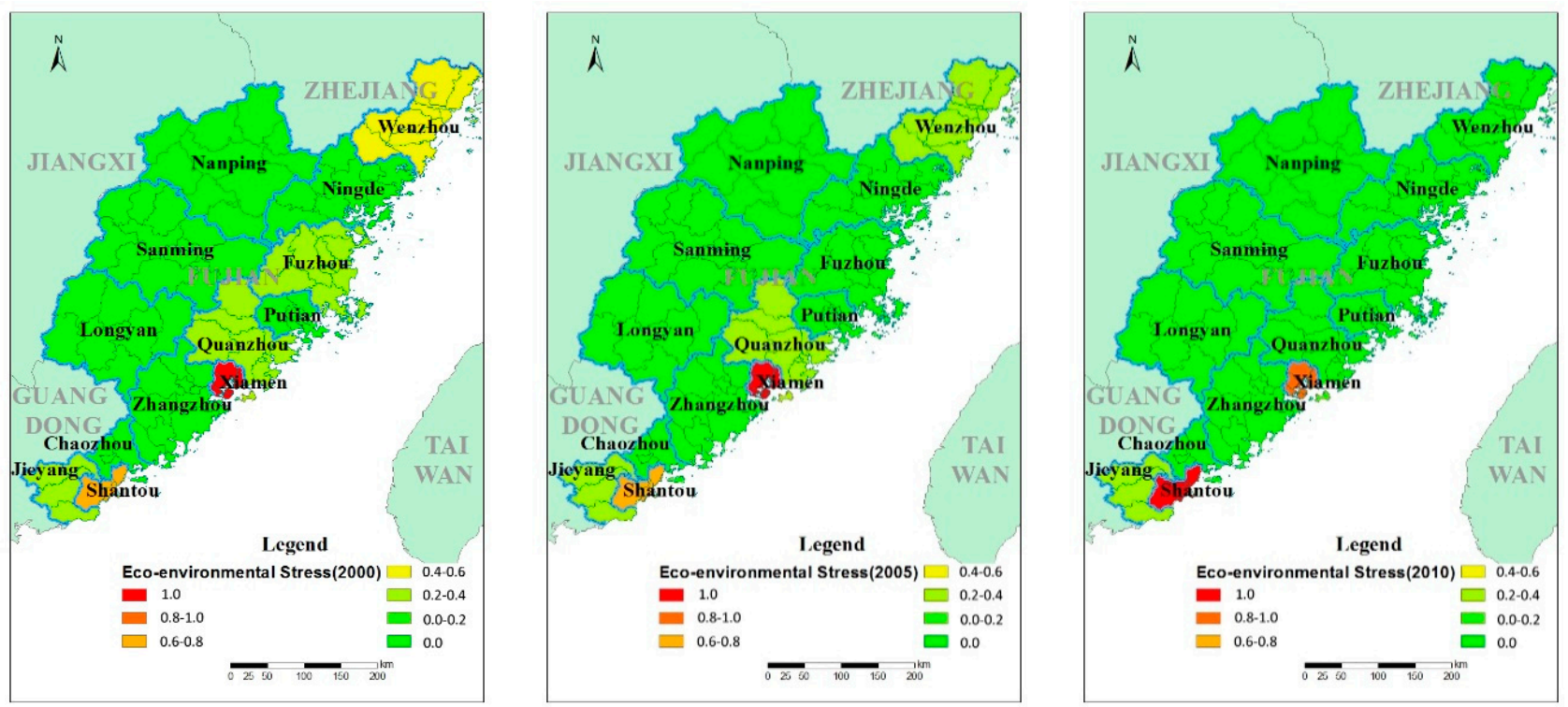

Figure 5. Graded map of ESI in Western Taiwan Straits Economic Zone.

\section{Conclusions and Recommendations}

(1) The overall condition of the Economic Zone's eco-environmental stress has not shown statistical differences during the period studied. The cities with the most severe eco-environmental stress are located in the north and south of the Economic Zone, i.e., in Zhejiang and Guangdong provinces. Those cities will be the key areas of pollution control in the future. Most parts of Fujian Province were less severely affected by eco-environmental stress, and the environment there showed steady improvement. The spatial layout of industrial development in the Economic Zone should be optimized on the basis of eco-environmental stress assessment. The regional industrial layout should be coordinated with national fundamental and strategic industrial layout. The overall planning of the Economic Zone should be formulated by relevant departments. The emphasis should be on coordinating the development layout of key industries within the Economic Zone. A disordered, unprioritized layout and malignant competition should be avoided.

(2) The atmospheric pollution of the Economic Zone increased during the period studied, with $\mathrm{SO}_{2}$ emissions showing a generally increasing trend. The cities with the highest $\mathrm{SO}_{2}$ emissions are concentrated in eastern coastal regions of the Economic Zone, and there is a trend of $\mathrm{SO}_{2}$ emissions spreading away from Economic Zone. The spatial distribution of industrial smoke and dust emissions was fairly even during the period studied. There were few cities with extremely high or low emissions. The spatial distribution of industrial smoke and dust emissions is becoming even flatter. Overall, water pollution in the Economic Zone decreased in the past 10 years during the period studied, with COD emissions first increasing and then decreasing. The area of cities with high COD emissions per unit land area represents a small proportion of total land area of the Economic Zone. The cities with the most severe pollution are located in the northern, middle, and southern parts of the Economic Zone. The 
distribution pattern did not show a tendency of outward diffusion. The cities with the highest sewage emissions are concentrated in the middle part of the Economic Zone, and there was no significant difference in this indicator between coastal cities and inland cities.

A mechanism for combined prevention and control of pollution that involves different regions and departments should be established in the Economic Zone. The purpose of such a mechanism would be to coordinate different departments in the management, monitoring, control, and prevention of pollution. There should be concerted efforts in the management of the regional atmospheric environment and the water environment of drainage basins. The pollution management of the land and ocean should be coordinated, with attention also given to rivers. The mechanism for joint prevention and control of pollution should be established with the features of unification of planning, monitoring, supervision, and assessment. The overall level of regional pollution prevention and control should be elevated. A comprehensive prewarning and response mechanism with linkages to all relevant departments should be established, and an emergency response plan for sudden pollution events should be formulated. An emergency response team for handling environmental pollution accidents should be built to ensure regional environmental safety. The regional environmental monitoring system should be improved to the extent possible. A system of combined monitoring and digitalized environmental notifications, established on a basic database of regional environment data should be built to provide support for environmental research, and the mitigation and control of accumulated pollution.

(3) The key industries of the Economic Zone are located mainly in coastal regions. In mountainous inland regions, the necessity of environmental preservation usually means less opportunity for key industrial development. Those regions cannot enjoy the benefits brought by the development of key industries. An imbalance of development between different regions is often associated with huge regional economic differences, which dampens the enthusiasm for environmental preservation in mountainous regions. In addition, the pollutant emissions in key development regions will directly and indirectly influence the local environment. Therefore, it is necessary to establish an ecological restoration and compensation mechanism in key regions of environmental preservation in the Economic Zone.

\section{Acknowledgments}

This research was supported by the National Science and Technology Support Program (2013BAJ04B01) and the Special Project on Remote Sensing Survey and Assessment of National Ecological Environment Change in Ten Years (2000-2010) (STSN-11-02).

\section{Author Contributions}

Longyu Shi designed and performed the research. Shuncheng Yang analyzed the data and wrote the paper. All authors read and approved the final manuscript.

\section{Conflicts of Interest}

The authors declare no conflict of interest. 


\section{References}

1. Sun, G.; Zhou, D.W. Progress in stress ecology. Rural Eco-Environ. 1999, 15, 42-46. (In Chinese)

2. Tang, J.; Si, A.; Li, H.Y.; Wang, X.G. Application of fractal theory to research on eco-environmental stress in west Songnen Plain. J. Ecol. Rural Environ. 2007, 23, 9-15. (In Chinese)

3. Miao, H.; Wang, X.K.; Ou Yang, Z.Y. Study on regionalization of eco-environmental stress process in China. Acta Ecol. Sin. 2001, 21, 7-13.

4. Gao, J. Study on Ecological Environmental Impact Integration Assessment Method; Jilin University: Jilin, China, 2007. (In Chinese)

5. Borics, G.; Várbíró, G.; Padisák, J. Disturbance and stress: Different meanings in ecological dynamics? Hydrobiologia 2013, 711, 1-7.

6. Inhaber, H. Environmental quality: Outline for a national index for Canada. Science 1974, 186, 798-805.

7. Hope, C.; Parker, J.; Peake, S. A pilot environmental index for the United Kingdom in the 1980s. Energy Policy 1992, 20, 335-343.

8. Adriaanse, A. Environmental Policy Performance Indicators: A Study of the Development of Indicators for Environmental Policy in The Netherlands; Uitgeverij: The Hague, Netherlands, 1993.

9. Erechtchoukova, M.G.; Khaiter, P.A.; Golinska P. Sustainability Appraisal: Quantitative Methods and Mathematical Techniques for Environmental Performance Evaluation; Springer: New York, NY, USA, 2013.

10. Giannetti, B.F.; Bonilla, S.H.; Silva, C.C.; Almeida, C.M. The reliability of experts' opinions in constructing a composite environmental index: The case of ESI 2005. J. Environ. Manag. 2009, 90, 2448-2459.

11. Cengiz, T. A methodology to analyze the relations of ecological footprint corresponding with human. Int. J. Sustain. Dev. World Ecol. 2013, 20, 9-19.

12. Kamal-Eldin, A.; Andersson, R. A multivariate study of the correlation between tocopherol content and fatty acid composition in vegetable oils. J. Am. Oil Chem. Soc. 1997, 74, 375-380.

(C) 2015 by the authors; licensee MDPI, Basel, Switzerland. This article is an open access article distributed under the terms and conditions of the Creative Commons Attribution license (http://creativecommons.org/licenses/by/4.0/). 